\title{
IVÁN RUIZ
}

\section{Antoni Tàpies}

\section{(I923-2012)}

El esfuerzo al que tiende mi obra consiste en recordar al hombre lo que en realidad es, en darle un tema de meditación, en producirle un choque que le haga salir del frenesí de lo inauténtico para que se descubra a sí mismo y tenga conciencia de sus posibilidades reales.

Tàpies, 1963

\section{El hombre de laboratorio}

E N UNA ÉPOCA MARCADA POR UNA PROFUNDA desazón respecto al lugar de la pintura dentro de los complejos dispositivos de arte contemporáneo, la muerte de Antoni Tàpies representa, sin lugar a dudas, una pérdida significativa en el campo de las artes plásticas. Tàpies no sólo fue uno de los principales exponentes del informalismo en el escenario de las vanguardias internacionales del siglo xx; el artista catalán también escribió un conjunto notable de textos críticos sobre las funciones social y política del arte. Nada extraño para un pintor con espíritu y formación libresca ${ }^{\mathrm{I}}$ que padeció los estragos de la guerra civil, desarrollando una primera etapa de su trabajo

I. Tàpies rememora: "Cuando en 1942 me diagnosticaron que tenía una lesión pulmonar y que debía ir a un sanatorio, me creí obligado a leer La montaña mágica [...] En cama tenía todo el tiempo para leer y pensar. Devoré prácticamente la novela rusa y francesa; también Unamuno, Nietzsche y Schopenhauer. Me gustaba Hamsun porque siempre he sentido una gran atracción por la naturaleza nórdica: bosques, lagos, fiordos... Asi habló Zaratustra y Los hermanos Karamazov dejaron en mí una huella profunda. Recuerdo haber llorado por Alio- 
en un clima árido como el que vivió España bajo la dictadura franquista. Al respecto, en un escrito sobre el motivo del muro en su obra, Tàpies recuerda que las imágenes murales "vienen de mi adolescencia y de mi primera juventud encerrada entre los muros en que viví las guerras [...] Todos los muros de una ciudad, que por tradición familiar me parecía tan mía, fueron testigos de todos los martirios y de todos los retrasos inhumanos que eran infligidos a nuestro pueblo".

Antoni Tàpies i Puig, condecorado en 20 Io por el rey Juan Carlos I como marqués de Tàpies por su contribución a las artes plásticas, nació el I3 de diciembre de 1923 en Barcelona y falleció a los 88 años en su casa de la calle de Zaragoza, el 6 de febrero de 2or 2. Si bien en un primer momento se matriculó en la Facultad de Derecho, hacia los años cuarenta orientó su formación, de modo autodidacta, hacia el dibujo y la pintura. Un rasgo distintivo de Tàpies, presente hasta sus últimos días en los cuales no dejó de producir, fue su vocación experimental, la cual debe entenderse en un sentido amplio y no sólo como un gesto de ruptura. En primer lugar, como un sello distintivo que recorre toda su obra y que responde a la singular elección y tratamiento de materiales artísticos, mixturas, colores y motivos iconográficos; en segundo término, lo experimental concebido como una actividad propia del laboratorio de investigación, por medio de la cual la función del pintor se equipara a la de un científico. Tàpies insistió en que el pintor debe ir codo a codo con el filósofo, el científico e incluso el político progresista: "El artista participa, en cierta manera, de todos, ya que investiga, descubre, defiende y propaga una idea igual que ellos". ${ }^{3}$

La idea de que el artista es un hombre de laboratorio es familiar a un grupo de pintores, los cuales hicieron de su taller de pintura un auténtico laboratorio de ideas e imágenes, tal como nos ha sido transmitido a través de una serie de construcciones fotográficas que, mediando entre el registro documental y el ensayo de autor, muestran el atelier como un centro de experimentación. ${ }^{4}$ En

scha”. "Tres entrevistas", en El arte contra la estética, Joaquim Sempere (trad.), Barcelona, Ariel, 1978, pp. 193-194.

2. Antoni Tàpies, "Comunicación sobre el muro", en Antoni Tàpies, La práctica del arte, Joaquim Sempere (trad.), Barcelona, Ariel, 1973, p. I38.

3. Tàpies, "La vocación y la forma", en ibidem, p. 25.

4. Destaco dos catálogos relativamente recientes: Freud at Work, con fotografías de Bruce Bernard y David Dawson (Nueva York, Alfred A. Knopf, 2006), y L'Atelier de Francis Bacon, con fotografías de Perry Ogden (Londres, Thames \& Hudson, 200I). 
este sentido, un retrato de I99I que captura a un Tàpies con las manos manchadas de pintura negra, mientras ejecuta una pieza en su taller, es simbólico: el vigor de su postura, la contundente mirada frontal, el gesto decisivo... revelan el temperamento de un pintor que lidia con sus materiales en un proceso riguroso y no por ello menos enigmático. El catalán hablaba de una especie de electricidad al momento de pintar: "El artista, sin necesidad de reglas, proyecta como una sustancia psíquica en el material. Esta proyección es lo esencial. Lo que cuenta, en efecto, es esta especie de electricidad, algo profundo, una cualidad humana (no digo sobrehumana), algo importante que hay que decir y que se proyecta sobre la obra de arte".5

\section{El campo de batalla}

La partida de Tàpies se suma a la de una estela de pintores — entre ellos, Francis Bacon, Balthus y Lucian Freud- que dotaron a la pintura de un carácter autorreferencial; epígono de todo un movimiento reflexivo, formalizado en el expresionismo abstracto, mediante el cual la pintura se pensó y se definió como Pintura, y no ya como un arte que "encubría el medio y usaba el arte para ocultar el arte". ${ }^{6}$ Dentro de este grupo, hermanado por un interés genuino tanto en la gestación inicial de la obra como en el envión que nos dirige hacia la meditación intensiva sobre las formas pictóricas, Tàpies destaca además por una indagación radical en las materias heterogéneas que son susceptibles de habitar la pintura.

Una de sus obras tempranas, Collage del papel de plata (1946), anticipa el trabajo de experimentación sobre las materias que definirá, en términos globales, la práctica pictórica del artista catalán: sobre una base de cartón, el encadenamiento de hilos produce una especie de red, en la cual destacan algunas zonas donde se encuentran pegados pedazos de papel aluminio, ya estirado y por tanto con marcas de irregularidad. La tensión que genera este papel plateado se debe, precisamente, a la extrańeza que produce su incorporación en una superficie donde se hallan dos materiales comunes entre sí (el hilo y el cartón). $\mathrm{Si}$ bien es innegable que este collage se inscribe en una vanguardia que trasto-

5. Tàpies, "Declaraciones", en La práctica del arte, op. cit., p. 42.

6. Clement Greenberg, "La pintura moderna” [1960], en Clement Greenberg, La pintura moderna y otros ensayos, Fèlix Fanés (trad.), Madrid, Siruela, 2006, p. II2. 
ca los límites de las artes en busca de una experiencia artística integral, regida en buena medida por los vasos comunicantes entre la vigilia y el sueño, 7 como pieza de autor, Collage del papel de plata nos introduce en un aspecto clave de la poética de este artista: la lucha con las materias, entendiendo por este último concepto todo aquello que está tomado de algún lugar del mundo y que se emplea para la fabricación de la obra de arte.

La atención que Tàpies prestó al proceso de transfiguración de la materia, convocando una filiación con la alquimia subyacente tanto en el collage ${ }^{8}$ como en las culturas de Oriente, ${ }^{9}$ trasciende todo esfuerzo de periodización estilística sobre su obra, pues podemos decir que antes de que su pintura fuera calificada como informalista ${ }^{\text {IO }}$ (en especial, a raíz de un conjunto de pinturas que produjo entre 1953 y 1969), el catalán ya poseía una conciencia sobre la gravedad de la materia y el proceso al que ésta tenía que ser sometida durante el acto creativo. En uno de sus escritos, Tàpies recuerda: "El artista se halla completamente solo ante su tela blanca y se enfrenta con problemas inherentes al

7. Hay que recordar que en 1948 Tàpies se convierte en uno de los fundadores del movimiento Dau al Set, nombre de la revista literaria homónima creada por el poeta Joan Brossa, donde se proclama la libertad del arte a través de filiaciones con el surrealismo y el dadaísmo. Brossa fue una persona clave en la vida de Tàpies; él mismo relata el influjo de este poeta después de haberlo conocido en I946: "En seguida sentí una gran atracción y admiración por Brossa: era el de más edad, poseía un bagaje cultural infinitamente superior al nuestro y nos sirvió de guía durante aquellos años [...] Fue Brossa, pues, quien supo echar un puente sobre el abismo que había abierto la guerra civil y establecer un enlace con los principales vanguardismos de aquella época que había quedado totalmente truncada". "Tres entrevistas", op. cit., p. 200.

8. Según Louis Aragon, el collage restituye "el verdadero sentido a los viejos planteamientos pictóricos, impidiendo que el pintor se entregue al narcicismo, al arte por el arte, volviendo a las prácticas mágicas, que son el origen y la justificación de las representaciones plásticas". "El desafío a la pintura" [1930], en Los colages, Pilar Andrade (trad.), Madrid, Síntesis, 200I, p. 47.

9. "De Oriente me interesaba todo: el arte de aquellos pueblos no puede admirarse independientemente de la filosofía, la religión, la sociedad, etc. Por otra parte, la vertiente mágica siempre ha ejercido una gran atracción sobre mí. Profundizar en aquellas culturas estimulaba mi imaginación y desprendía una gran fuerza de sugestión; me permitía trasladarme a un mundo que, de hecho, me parecía más real que aquel en que me veía forzado a vivir.” Tàpies, "Tres entrevistas", op. cit., p. 196.

ı. La calificación obedece al concepto de "informalismo", término acuñado por Michel Tapié hacia I95 I para destacar el papel central de la materia en la obra de un grupo de pintores, quienes representaban la contraparte del núcleo de expresionistas abstractos en Estados Unidos. "Art Informel” y "Art Autre” fueron fórmulas empleadas para describir el fulgor de la materia en la pintura de Dubuffet, Wols, Michaux y Fautrier, entre otros. 


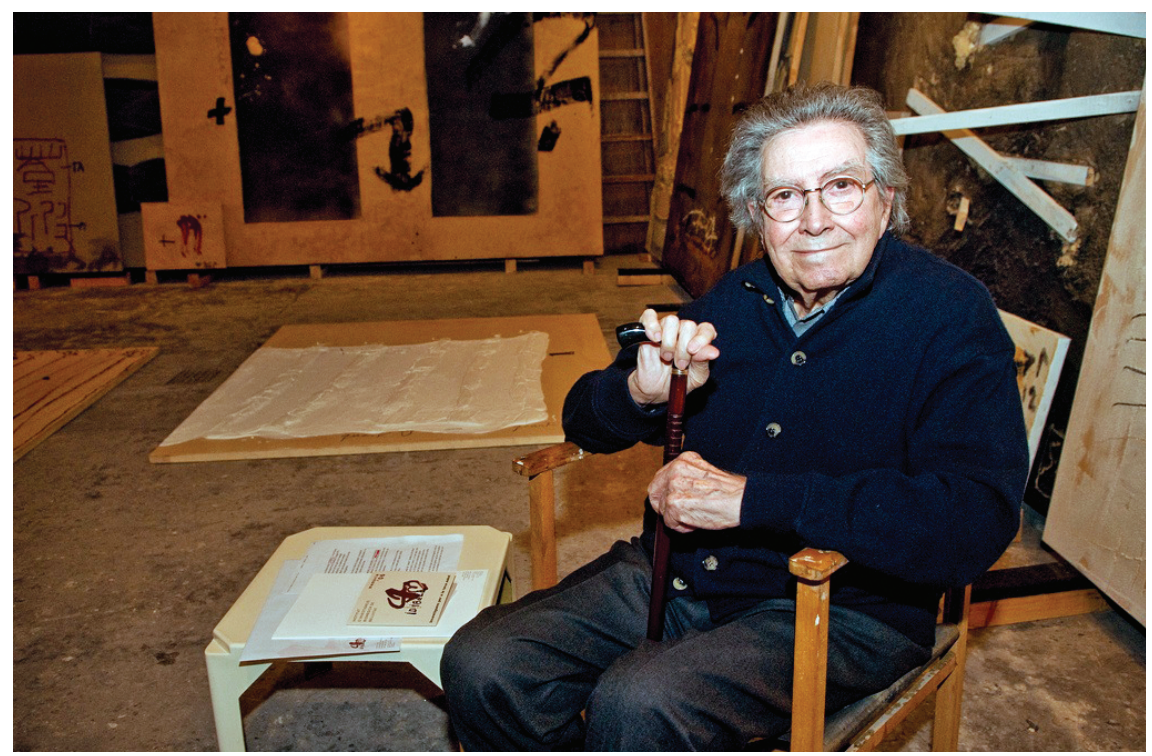

I. Antoni Tàpies. Foto: CCBY-ND2.o/calanhub@yahoo.com.es.

arte, ya que éste tiene leyes propias", y de inmediato subraya que esta suerte de meditación frente a la tela tiene que estar acompañada de "una lucha con la materia peculiar suya". I Si volvemos al Collage del papel de plata, observaremos cómo el conflicto textural, lumínico y matérico que el papel de plata introduce en el soporte de cartón, dominado por un cromatismo marrón, constituye un destello de singularidad y es precisamente este centelleo el que permite reconstruir, para un observador atento, "el milagro según el cual unos materiales, que por sí solos son inertes, empiezan a hablar con una fuerza expresiva que difícilmente puede compararse a ninguna otra cosa”. ${ }^{\text {I2 }}$

Además de las tensiones que se observan a partir de los encabalgamientos entre materiales tan heterogéneos entre sí, Tàpies también puso de manifiesto la lucha con las materias mediante una serie de actividades manuales que hacen de la superficie pintada un espacio de vibraciones ópticas y táctiles. Grattage sobre cartón (I947), Tela encolada (196I), Relieve gris en cuatro partes (I963), El espiritu catalán (I97I), Libro-muro (I990), entre otras piezas, recu-

I I. "Arte-idea", en La práctica del arte, op. cit., p. I9.

I2. "La vocación y la forma", en ibidem, p. 27. 
rren a diferentes técnicas que hieren la solidez de la materia para presentarla en un estado de desgarramiento o de franco deterioro. Digamos que en este tipo de pinturas rasgadas, frotadas, manchadas, sobrecargadas, Tàpies hizo patente el trance que supone el paso de la meditación a la acción, de la perplejidad que evoca un blanco dominante de la tela a la actividad colorida de inscripción pictórica. "Cada tela — escribió este pintor- era un campo de batalla en el que las heridas se iban multiplicando cada vez más hasta el infinito." ${ }^{33}$ Los lienzos lacerados de Tàpies, asociados por un aire de tiempo con las telas perforadas de Lucio Fontana y los lienzos escurridos de Francis Bacon, son una muestra emotiva de la impronta que la posguerra dejó en todo un núcleo de pintores a quienes les fue imposible sustraerse de su realidad inmediata y que, no obstante el peso de tal visión trágica de la humanidad, construyeron otra realidad, la de la pintura misma, que posee sus propias leyes de composición y de supervivencia.

\section{La función de las formas}

Así como la lucha con las materias circundó el campo de batalla - la trinchera desde donde Tàpies ejercitó sin tregua su experimentación pictórica一, la vida pública de esas formas, esto es, su transferencia o su inscripción en la comunidad, merece también una reflexión particular. Al respecto, la postura del artista era implacable: "Si las formas no son capaces de herir a la sociedad que las recibe, de irritarla, de inclinarla a la meditación, de hacerle ver que está atrasada, si no son un revulsivo, no son una obra de arte auténtica". ${ }^{14}$ Lo que se pone en juego en esta declaración tiene que ver, en principio, con la concepción cientifica del artista: si éste es como un hombre de laboratorio, es porque sus ideas, sus conceptos, sus invenciones permiten ejercer un avance y un autoconocimiento de las disciplinas en cuestión y, finalmente, de los modelos sociales y las construcciones culturales en que ellas se asientan. Este último rasgo es fundamental para comprender la importancia de la pintura de Tàpies en su propio país, en especial, a raíz de los procesos complejos de represión y libertad que caracterizaron los años en que produjo su obra más representativa. Precisamente, el catalán subraya lo siguiente: "si la misión de los artis-

I3. "Comunicación sobre el muro", en ibidem, p. I39.

I4. "Arte-idea”, en ibidem, p. 20. 
tas y poetas es promover la reflexión, suscitar y atraer la atención, dar a conocer, iluminar la realidad y, en suma, exaltar todo cuanto nos haga más libres y más perfectos como humanos, ¿olvidaremos o infravaloraremos el hecho de que la historia de la formación de nuestro país coincide justamente con la historia de la conquista de la libertad y con el avance democrático del mundo?"Is

Pero claro está que, por fraguarse en un momento de constante redefinición y ajuste de la emancipación política de un país como España, la pintura con este linaje corre el riesgo de convertirse en un recurso panfletario, o bien, de exigir que su creador se adhiera a determinados eventos que legitimen o esclarezcan la ideología de su producción. ${ }^{16}$ Tàpies rehuyó este tipo de operación que simplifica los nexos entre arte y política, con el fin de llamar la atención sobre cómo una sensibilidad politizada puede modelar una constelación de formas críticas y, en tal medida, reposicionar la noción de vanguardia como un auténtico tour de force sobre el discurrir convencional de la historia y la estética. Desde esta perspectiva crítica, afirmar, como lo hizo el catalán, que el drama político de España está encarnado en sus piezas ${ }^{17}$ equivale a pensar en un proceso por medio del cual la observación atenta de las materias se transforma, mediante esa alquimia fundante, en un análisis susceptible de evocar otros planos que afectan a la sociedad, a la política y a la moral. No se trata, entonces, de encontrar o postular una materia con un contenido a priori, sino de transfigurar la materialidad para dar vida a una estela de formas animadas por ese impulso científico, creativo e ideológico.

Para Tàpies, las formas están destinadas a irrumpir en la enajenación de una sociedad particular y a producir, más allá de una dislocación de la mirada, una reflexión sobre la libertad concebida como una práctica de vida cotidiana que involucra los niveles de conceptualización, acción y reflexión y por ello es tanto inteligible como sensible, pues el arte "actúa sobre nuestra sensi-

I5. "El arte de vanguardia y el espíritu catalán”, en El arte contra la estética, op. cit., p. 34.

I6. "Es la cantinela de siempre, el tic obsesivo de que el creador es más social, más progresista, por hechos ańadidos o accesorios. No por su propia obra, no por lo que ha dicho en su propio terreno. En el fondo equivale a seguir sin creer en el arte de vanguardia, a no tener sensibilidad para la nueva poesía. Una especie de vanguardismo vergonzante o un 'realismo social' encubierto." Tàpies. "Vanguardismo y colectividad", en ibidem, p. II8.

I7. "Si pinto como pinto es, en primer lugar, porque soy catalán. Pero siento, como tantos, el drama político de España. Éste saldría en mis obras aunque no me lo propusiera." "Declaraciones", en La práctica del arte, op. cit., p. 44. 
bilidad general y no exclusivamente sobre la inteligencia". ${ }^{8}$ La función de las formas contribuye a enriquecer una actividad espiritual densa, donde idea y materia, por medio de jirones, desarman una visión laxa del mundo y exigen el ejercicio de la sensibilidad a través de un activismo intelectual.

\section{El trovador}

Tàpies, pintor, hombre de laboratorio, marqués..., tuvo también otra personalidad: la de un noble trovador que escribe y canta versos desde lo profundo de su corazón, desgarrado por la guerra y exaltado por la posibilidad del arte. En 1963, él mismo describió un diagnóstico autobiográfico que hoy, tras su desaparición física, cobra mayor intensidad en la redimensión de su figura, no sólo en la historia del arte, sino en esa posibilidad de reconocimiento del otro, y de lo otro, que define a lo humano: "Puesto que soy un trovador que canta para su pueblo, el del país en que vivo y el de todas partes, no es de extrańar que busque la amistad de todos, de los hombres y de las bestias, de los árboles y de las piedras". ${ }^{19}$ के

I8. Ibidem, p. 36.

19. Ibidem, p. 39. 